\title{
SMART CITIES: COMO O CONCEITO DE CIDADES INTELIGENTE PODE MELHORAR A MOBILIDADE URBANA NA CIDADE DO RIO DE JANEIRO
}

\author{
Marcone Freitas dos Reis \\ Centro de Tecnologia da Indústria Química e Têxtil (SENAI CETIQT) \\ Rua Magalhães Castro, 174 - Riachuelo, Rio de Janeiro - RJ, 20961-020 \\ marconefreis11@gmail.com \\ Pâmela Teixeira de Andrade \\ Centro de Tecnologia da Indústria Química e Têxtil (SENAI CETIQT) \\ Rua Magalhães Castro, 174 - Riachuelo, Rio de Janeiro - RJ, 20961-020 \\ riogoproducoes@gmail.com
}

Marcos dos Santos

Instituto Militar de Engenharia (IME)

Praça General Tibúrcio, 80 - Praia Vermelha - Urca, Rio de Janeiro - RJ, 22290-270 marcosdossantos_doutorado_uff@yahoo.com.br

\section{Angélica Rodrigues de Lima}

Centro de Tecnologia da Indústria Química e Têxtil (SENAI CETIQT)

Rua Magalhães Castro, 174 - Riachuelo, Rio de Janeiro - RJ, 20961-020

angelicadelima.engprod@gmail.com

\section{Alexandre Camacho da Paixão}

Universidade Estácio de Sá (UNESA)

Av. Dom Hélder Câmara, 5.474, 4 Piso Norte Shopping, Cachambi - RJ, 20771-004

alexandrecpaixao@yahoo.com.br

\section{RESUMO}

A mobilidade urbana é sensivelmente afetada pelo crescimento desordenado das cidades. Muitos problemas dos centros urbanos atualmente são ocasionados pelo aumento do número de automóveis nas ruas e os pouco incentivos ao transporte coletivo são apenas alguns desses transtornos. O acelerado crescimento urbano registrado nos últimos anos faz com que a preocupação aumente em relação à mobilidade urbana na cidade do Rio de Janeiro. As cidades inteligentes, é uma alternativa para os problemas encontrados nas cidades onde, a partir da Tecnologia da Informação, busque base de dados, e com isso compartilhe informações importantes com a participação efetiva da população, ajudando a própria gestão a fazer algo pelo cidadão carioca. Nos últimos oito anos, há um número excessivo de pessoas e veículos ocupando as ruas, gerando congestionamentos, insegurança e perda de tempo, como base na estatística da empresa Holandesa Tom Tom, o Rio de Janeiro perde em média $47 \%$ a mais do seu tempo no trânsito em relação ao tempo perdido ao redor do mundo. O objetivo deste estudo é apresentar como o conceito de cidades inteligentes pode influenciar na mobilidade urbana, através, da sustentabilidade, inovação, pesquisas através de estatística mundial, inteligências entre as cidades mundiais, no intuito de trazer melhorias para os congestionamentos e dificuldade de circulação na cidade do Rio 
de Janeiro. Portanto, neste estudo foi utilizado além de dados estatísticos, materiais de Smart cities e mobilidade urbana no mundo atual, como demonstrar diferentes formas de mobilidade urbana em cidades inteligentes através do uso de aplicativos de interação entre pessoas e cidades.

Palavra-chave: Cidades Inteligentes; Mobilidade urbana; Internet das coisas.

\begin{abstract}
Urban mobility is significantly affected by the disorderly growth of cities. Many problems in urban centers today are caused by the increase in the number of cars on the streets, and poor incentives for public transport are just some of these disorders. The rapid urban growth registered in recent years causes concern to increase regarding urban mobility in the city of Rio de Janeiro. Smart cities, is an alternative to the problems encountered in cities where, from Information Technology, search databases, and thus share important information with the effective participation of the population, helping the management to do something for the carioca citizen. Over the past eight years, there have been too many people and vehicles taking to the streets, leading to traffic jams, insecurity and wasted time, based on Dutch company Tom Tom statistics, Rio de Janeiro loses an average of $47 \%$ more of its time. In traffic relative to the time wasted around the world. The aim of this study is to present how the concept of smart cities can influence urban mobility through sustainability, innovation, research through world statistics, intelligences between world cities, in order to bring improvements to congestion and difficulty of circulation in the city. City of Rio de Janeiro. Therefore, this study was used in addition to statistical data, Smart cities and urban mobility in the current world, how to demonstrate different forms of urban mobility in smart cities through the use of interaction applications between people and cities
\end{abstract}

Keywords: Smart Cities; Urban Mobility; Internet of Things.

\title{
Como Citar:
}

REIS, Marcone Freitas dos; ANDRADE, Pâmela Teixeira de; SANTOS, Marcos dos; LIMA, Angélica Rodrigues de; PAIXÃO, Alexandre Camacho da. Smart Cities: Como o conceito de cidades inteligente pode melhorar a mobilidade urbana na cidade do Rio de Janeiro. In: SIMPÓSIO DE PESQUISA OPERACIONAL E LOGÍSTICA DA MARINHA, 19, 2019, Rio de Janeiro, RJ. Anais [...]. Rio de Janeiro: Centro de Análises de Sistemas Navais, 2019.

\section{INTRODUÇÃO}

Segundo o relatório United Nations, Department of Economic and Social Affairs, Population Division (2015), a população urbana mundial já é maior que a rural, pois 54\% dos habitantes vivem nas cidades. Este número é significativamente superior ao observado na década de 1950, quando apenas 30\% encontravam-se em regiões urbanas. Dados recentes indicam uma completa inversão em 2050, sugerindo que somente 34\% residirão em regiões rurais. A evolução da população urbana e rural mundial desde 1950 até 2050, conforme as projeções calculadas pelas Nações Unidas. Em 1950, apenas 700.000 pessoas viviam nas áreas urbanas; em 2014, cerca de 3,9 bilhões de indivíduos estavam nos centros urbanizados; por fim, estima-se que este número alcançará 6,3 bilhões em 2050. 
De acordo com o índice do IBEU (Bem-Estar Urbano), elaborado pelo observatório das metrópoles de 2013, entre as 15 regiões metropolitanas do Brasil, a do Rio de Janeiro é a que tem a pior avaliação no quesito mobilidade urbana, estando abaixo da média nacional em todas as dimensões analisadas. (RIBEIRO E RIBEIRO, 2013)

As dificuldades enfrentadas pelos cidadãos em seus deslocamentos diários criam barreiras principalmente para os mais pobres e que residem afastados das áreas que concentram as melhores oportunidades de estudo e de trabalho. O resultado mais notável dessa afirmação é que o processo de exclusão social se agrava ainda mais com a existência de um sistema de transporte público deficiente. (PERO E MIHESSEN, 2012)

Nesse contexto são grandes os desafios para encarar os projetos de cidades inteligentes, ainda mais se entender como "inteligência" os processos que estimulam à criatividade, o criticismo, a democratização e não somente a adoção de tecnologias digitais. As iniciativas não vão, necessariamente, criar uma metrópole mais sensível e promissora apenas por oferecer objetos com sensores interligados a redes digitais. Sem uma discussão política em relação às novas ferramentas informacionais, nada garante que teremos, no futuro, cidades de fato mais inteligentes. (LEMOS, 2013)

Para Sonda (2017) cada vez mais comum no mundo inteiro, o conceito de Smart City está transformando cidades inteiras ao usar tecnologia e inteligência na gestão pública. A forma mais simples e direta de fala sobre o assunto é considerar que cidades inteligentes são aquelas que usam dispositivos conectados para monitorar e gerenciar as ruas e os espaços públicos. O conceito, porém, vai muito, além disso. Em seu significado mais amplo, Smart Cities são centros urbanos que vêm incorporando tecnologias e soluções de TI (Tecnologia de Informação) para integrar e otimizar as operações municipais, reduzindo custos e melhorando a qualidade de vida de seus habitantes, diminuindo tempo ocioso e aumentando a produtividade. Uma cidade que atinge esse patamar, portanto, não é apenas conectada, mas sim uma região viva e sustentável que consegue usar a inteligência a favor da administração e da gestão de recursos, além de garantir mais segurança e praticidade no uso de vias e outros aparatos públicos.

Segundo Villarino (2017) quando falamos de revolução tecnológica, a noção da Internet das Coisas (IoT - Internet of Things), é um dos assuntos principais. E não é difícil entender o porquê. Suas possibilidades são inúmeras, como transformar nossa relação com a tecnologia, mudar o modo como interagimos com o mundo e até mais, o modo como o mundo interage conosco. É um conceito capaz de mudar não só como nós vivemos, mas também como se trabalha.

Neste estudo será apresentada a proposta da aplicação do conceito de cidades inteligentes, utilizando na prática o conceito de Smart City para melhorar a mobilidade urbana na cidade do Rio de Janeiro, através de recursos de sustentabilidade e integrações de sistemas inteligentes, propondo um aplicativo MOBILE URB para garantir uma melhor locomoção pela cidade com qualidade de vida, facilidade e acessibilidade aos cidadãos carioca.

\section{PROBLEMA}

A mobilidade urbana no Brasil virou um grande caos, sobretudo nas grandes metrópoles. Um problema que se agrava com o passar dos anos e afeta diretamente a população.

Assim, em cidades grandes do Brasil com população de 3 milhões de pessoas são realizados por dia 6 milhões de deslocamentos. Esses deslocamentos são feitos com maior ou menor nível de conforto conforme as condições específicas em que se realizam e implicam consumos de tempo, espaço, energia e recursos financeiros e geração de externalidades 
negativas, como a poluição do ar, os acidentes de trânsito e os congestionamentos. Em razão do intenso crescimento urbano no Brasil, a partir da década de 1960, muitas cidades - e regiões metropolitanas - passaram a apresentar sistemas de mobilidade de baixa qualidade e de alto custo, com impactos negativos na vida das pessoas e nos custos econômicos e ambientais para a sociedade. Assim, o estudo das condições efetivas de mobilidade é fundamental para avaliar a qualidade da vida urbana no país e para identificar ações de políticas públicas que possam reduzir os problemas e melhorar a qualidade geral de vida e a eficiência da movimentação de pessoas e mercadorias. (FERNANDES, 2015)

De acordo com a estatística da Tom Tom Traffic Index (2017) o Rio de Janeiro é a $8^{\circ}$ cidade mais congestionada do mundo e a primeira colocada no Brasil. Os cariocas passam em média $47 \%$ mais tempo parados no trânsito, a qualquer hora do dia, e até $81 \%$ a mais nos períodos de pico no final do dia em comparação a uma situação de fluxo livre, ou sem congestionamentos - acrescentando até 164 horas a mais de viagem por ano.

Com o objetivo de auxiliar o desdobramento dos assuntos a serem abordados neste estudo, elaborou-se o mapa mental representado na Figura 1 a seguir, onde apresenta os desdobramentos do problema e a proposta de implantação do conceito de Smart Cities para ajudar na mobilidade urbana da cidade do Rio de Janeiro.

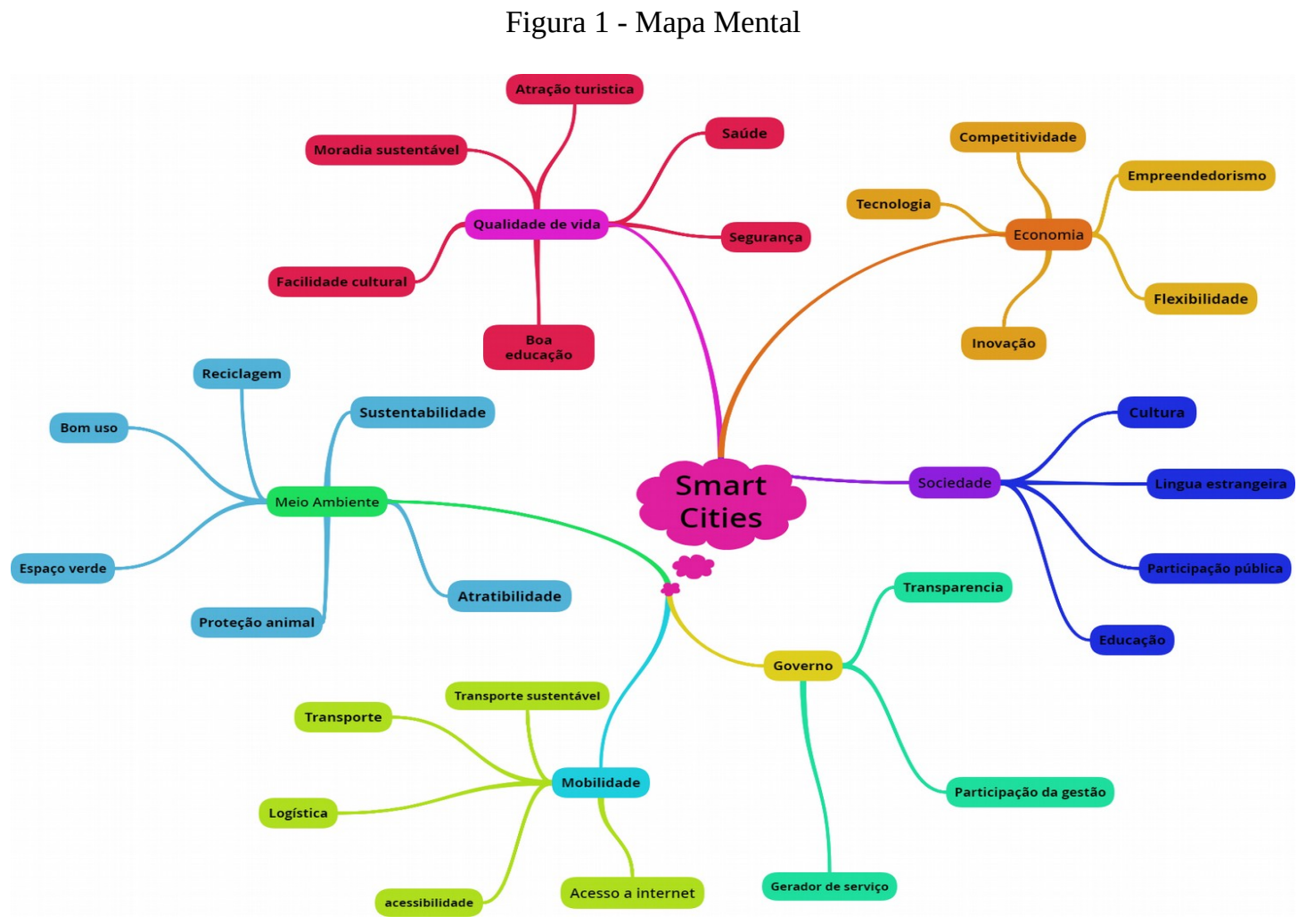

Fonte: Autores (2018)

\section{FUNDAMENTAÇÃO TEÓRICA}

\subsection{Cidades inteligentes}

Smart Cities são um misto de capital humano e tecnologia que tem por objetivo uma melhoria no desenvolvimento de uma cidade de forma sustentável. As Tecnologias de Informação e Comunicação (TIC) são utilizadas para viabilizar o crescimento econômico e uma melhora na qualidade de vida, uma boa gestão de recursos naturais e energéticos, com participação do Estado. Os investimentos são cinco principais áreas: meio ambiente, 
mobilidade, interação cidadão-governo, qualidade de vida e economia/pessoas criativas. (UE, 2017)

Giffnger et al. (2007) forneceram um modelo de Smart City, entendido como uma cidade composta de seis características construídas sob a combinação inteligente de doações e atividades de autogerenciamento, cidadãos conscientes e independentes e um método para medir e comparar a inteligência urbana. As seis características ou setores em que uma Smart City tem de garantir alta performance, segundo os autores, podem ser identificadas como: economia inteligente; pessoas inteligentes; governança inteligente; mobilidade inteligente; ambiente inteligente e; vida inteligente.

\subsection{MOBILIDADE URBANA}

Por décadas, os carros estiveram no centro do planejamento das grandes cidades. Com isso, mobilidade urbana era sinônima de infraestrutura viária para veículos automotores. O resultado? Engarrafamentos estratosféricos, saturação das vias e poluição severa. Mas, graças ao avanço da tecnologia, a Transformação Digital na mobilidade urbana está ampliando as soluções e permitindo novo olhar ao planejamento caótico das áreas urbanas. (EQUIPE TD, 2018)

A falta de mobilidade urbana é considerada como um dos maiores problemas enfrentados pelas grandes metrópoles. Os problemas encontrados na mobilidade urbana de uma cidade podem derivar de diversos fatores, entre eles: crescimento populacional desordenado e acelerado aliado a uma infraestrutura não preparada, incentivo ao uso do automóvel individual e falta de qualidade no transporte público. (XIMENES, 2016)

Muitos dos desafios encontrados em mobilidade urbana em países em desenvolvimento, como o Brasil, são umas combinações de problemas históricos e da crença que a principal maneira de tornar a mobilidade dos cidadãos melhor é o transporte individual, o automóvel. (SILVA, COSTA E MACEDO, 2008)

Segundo Silva, Costa e Macedo (2008) a questão de mobilidade no Brasil é tratada como uma questão de oferta de serviços de transporte, ou seja, oferta de infraestrutura de automóveis em detrimento do transporte coletivo, dos transportes não motorizados e a separação do planejamento urbano do planejamento do transporte.

De acordo com a revista exame (2016) cerca de $41 \%$ da população passa em torno de 1 a 4 horas no trânsito para se deslocar de casa para o trabalho, conforme pode ser observado na Figura 2 a seguir.

Figura 2 - Tempo de deslocamento no trânsito

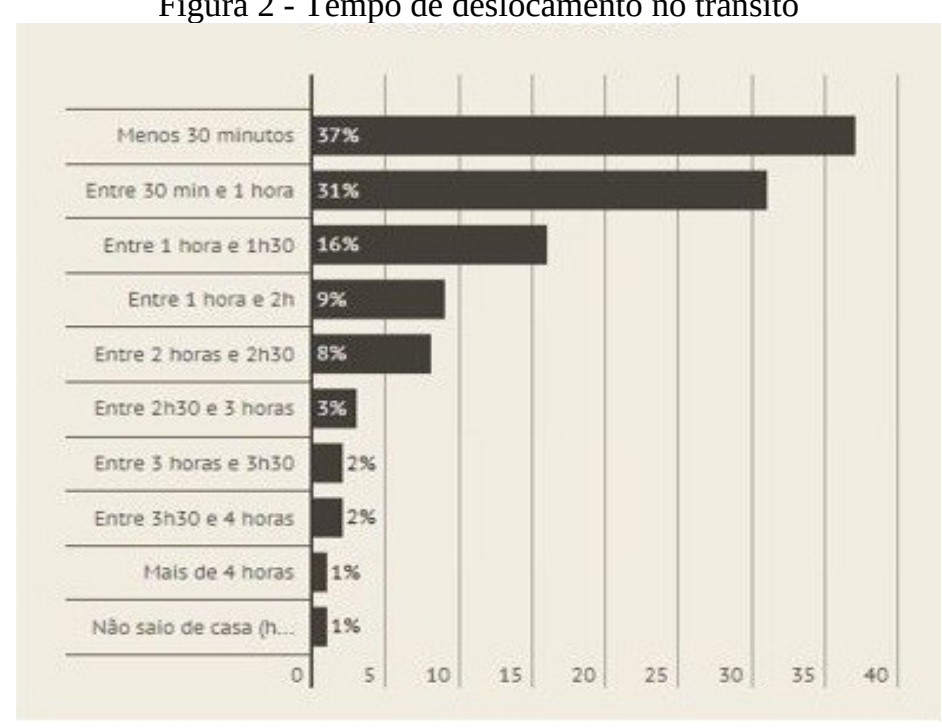

Fonte: Exame (2016) 


\subsection{INTERNET DAS COISAS}

De acordo com Werkema (1995), IoT ou Internet das Coisas refere-se à interconexão de computação embarcada identificável unicamente como dispositivo dentro da infraestrutura de Internet existente. Tipicamente a IoT oferece conectividade avançada de dispositivo, sistemas e serviços que vai além de comunicações entre máquinas (M2M) e abrange uma variedade de protocolos, domínios e aplicações. A interligação destes dispositivos embutidos (incluindo objetos inteligentes) deve dominar a automação em quase todos os campos e disponibilizar aplicativos avançados, como Smart Grids.

A arquitetura M2M é superada pela Internet of Things (IoT), isto é, os dispositivos eletrônicos passam a agregar não apenas capacidade de comunicação, mas também de processamento, tornando-se agentes inteligentes. Com o domínio dos países asiáticos no mercado globalizado da produção e distribuição de commodities, os preços desses sensores inteligentes, smartphones e outros artefatos tornam-se mais acessíveis às grandes massas e disponíveis para composição, pelos arquitetos de smart cities, em diversos arranjos formando plataformas de soluções cada vez mais sofisticadas. (HOLLER, 2014)

\subsection{OS APLICATIVOS E A MOBILIDADE URBANA}

De acordo com o site Statista (2014), de 2000 a 2014, houve um aumento de 1000\% de pessoas com acesso à internet. Além disso, deve-se destacar o aumento da utilização de aparelhos móveis, que, pela facilidade de mobilidade, auxiliam nas consultas e produção de conteúdo sobre as cidades. Estes aparelhos, geralmente, contam com GPS, que permite interação com os outros na área, proporcionando traçados de rotas, estimativas de tempo no trânsito e outras informações importantes para o usuário. Estes avanços facilitaram o acesso da população a aplicativos, que podem entreter e informar sobre diversos setores da cidade, inclusive sobre a mobilidade urbana. Hoje, é possível se locomover com facilidade em qualquer lugar do mundo com a ajuda de um aplicativo. É possível, ainda, saber as condições do trânsito antes mesmo de sair de casa, possibilitando a escolha de rotas melhores e mais vazias. Estas facilidades, que integram o conceito de smart cities, empoderam o usuário, visto que, com sua utilização, é possível a programação do tempo, os locais pelos quais se desejam passar e como estes caminhos serão feitos.

Segundo o site O Dia (2016) aplicativos para celular e outros avanços tecnológicos têm transformado as formas de ir e vir da população e podem ser grandes aliados na melhoria da mobilidade urbana. A terceira e última reportagem da série 'Tendências dos Transportes' mostra o potencial dessas novas ferramentas, sobretudo as de compartilhamento de carros, bicicletas e caronas, para criar cidades inteligentes e mais conectadas.

Segundo a UITP (União Internacional dos Transportes Públicos), simulações feitas nas capitais de países da União Europeia mostram que a combinação de transporte público de alta capacidade e o compartilhamento de carros e caronas poderia remover até 65 de cada 100 carros nos horários de pico. (O DIA, 2016)

\section{PROPOSTA DE SOLUÇÃO}

\subsection{A CIDADE}

O Rio de Janeiro é uma metrópole mundialmente conhecida por sua excepcional interação entre cultura e natureza e destino desejado pelos turistas do Brasil e do mundo. A intensa vida cultural e o centro histórico exuberante se unem à paisagem natural com muitos atrativos urbanos. São ícones do roteiro turístico carioca: a Floresta da Tijuca (considerada a maior mata urbana do mundo), as praias de Copacabana, Ipanema e Leblon, além do 
mundialmente famoso Pão de Açúcar com o vai-e-vem do seu Bondinho e o Corcovado com a estátua gigante do Cristo Redentor. Além de ser um dos cenários mais belos do Brasil e do mundo, as manifestações culturais do Rio de Janeiro expressam a síntese do estilo de vida do carioca, conhecido internacionalmente, e marcado pelo samba, a bossa nova, o futebol, o carnaval e a religiosidade - católica e de matriz africana. A Lapa com seus arcos famosos, no Centro Histórico, é uma das regiões mais visitadas pelos turistas, tanto pela integração cultural entre os visitantes e cariocas como pela vida boêmia e agitação noturna da cidade. (GURGEL, 2018)

Com 453 anos e cerca de 17,2 milhões de habitantes, o Rio de Janeiro conforme mostra a Figura 3 a seguir, é o terceiro estado mais populoso do país, conforme a estimativa populacional divulgada pelo Instituto Brasileiro de Geografia e Estatística (IBGE). Ele fica atrás apenas de São Paulo, com 45,5 milhões de habitantes, e Minas Gerais, com 21 milhões. A população fluminense corresponde a aproximadamente $8 \%$ de toda a população do país, estimada pelo IBGE em 208,5 milhões de pessoas. A estimativa considera todas as pessoas que viviam no país até o dia $1^{\circ}$ de julho de 2018. (GLOBO, 2018)

Figura 3 - Fotografia da cidade do Rio de Janeiro

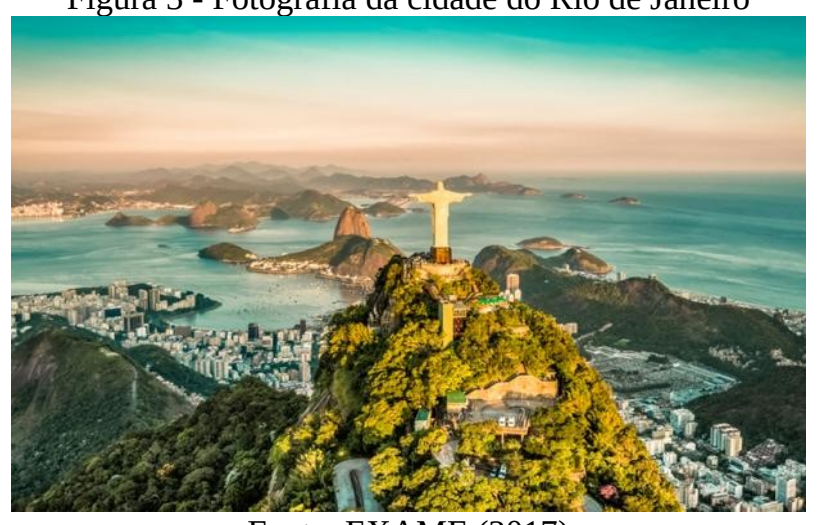

Fonte: EXAME (2017)

\subsection{CONTEXTUALIZAÇÃo DO PROBLEMA}

O problema de mobilidade urbana nas grandes cidades é um dos principais desafios para melhorar a qualidade de vida da população, apontou audiência pública pela Comissão Senado do Futuro (CSF). Moradores de regiões metropolitanas gastam até quatro horas no trajeto entre a casa e o trabalho. Eles defenderam maior integração entre municípios e participação popular na busca por soluções. (NOTÍCIAS, 2018)

Ainda Notícias (2018), a mobilidade é um tema amplo que ultrapassa a discussão sobre o trânsito, envolvendo questões relativas à história da ocupação dos territórios, ao crescimento econômico-social do país e às políticas públicas. Ela tem impacto direto sobre a saúde e a qualidade de vida das pessoas através dos principais problemas como congestionamentos, conflitos de diferentes modos de transporte, redução da segurança para os pedestres, aumento da poluição do ar e sonora, redução de áreas verdes devido ao espaço para estacionamentos e ampliação de vias para circulação dos veículos motorizados. Sugerindo além da urbanização sem planejamento, um dos motivos que levou o Brasil a chegar nesse ponto crítico da mobilidade foi à adoção de políticas públicas como a redução do imposto para compra de veículos, privilegiando o transporte individual motorizado.

Pode-se dizer que a ausência de mobilidade mais eficiente não gera somente consequências negativas na qualidade de vida das pessoas, mas também na economia do país devido ao aumento de tempo de deslocamento de casa para o trabalho, fator que gera prejuízo para as empresas pela redução de desempenho dos funcionários, seja pelo atraso ou 
pelo cansaço. E diante de todas essas informações, a cidade que foi escolhida para representar todos esses desafios da Mobilidade Urbana foi o Rio de Janeiro que, apesar da crise que tem vivido também tem adotado soluções para melhorar os deslocamentos e o padrão de vida da população.

Os principais problemas que ocorrem na cidade com frequência são:

- Tempo gasto de espera pelo transporte público;

- Distância percorrida;

- Usuários do transporte público que precisa fazer mais de uma troca de modal em uma única jornada;

- Alto custo do transporte publica comparada a renda mensal;

- Tempo gasto em congestionamento;

- Alto número de automóveis na rua;

- Inexistência de políticas de transporte público;

- Alta poluição atmosférica e riscos para a saúde da população.

\subsection{O APLICATIVO MOBILE URB}

Com o objetivo de proporcionar a sociedade melhor locomoção e interatividade, com intuito de uma melhor qualidade de vida para o cidadão carioca, com menor tempo no trânsito, e com uma mobilidade melhor para circular sobre a cidade, surge a ideia de desenvolver um aplicativo para smartphones, disponível para os sistemas operacionais Android, iOS e Windows Phone é capaz de interagir com o sistema ERP, que é um sistema de informações que integra todos os dados e processos de uma organização em um único sistema que será utilizado para a mobilidade do Rio de Janeiro.

\subsubsection{Acesso ao Mobile Urb}

Para ter acesso ao aplicativo Mobile Urb é necessário buscá-lo na loja virtual do sistema operacional do smartphone. Após solicitar a instalação gratuita dele, mediante a conclusão deste processo, basta acessá-lo no aparelho.

Na figura 4 a seguir, é apresentada a tela inicial ao usuário para cadastro de e-mail pessoal e senha, em seguida o usuário é direcionado para fazer um cadastro que possui informações como: endereço residencial, endereço do trabalho, telefones para contato e cadastramento de cartão de crédito, débito ou dinheiro. Após a primeira vez que o cliente acessar essa tela, o Mobile Urb armazenará suas informações e, ao acionar o aplicativo, ele terá acesso direto ao menu principal.

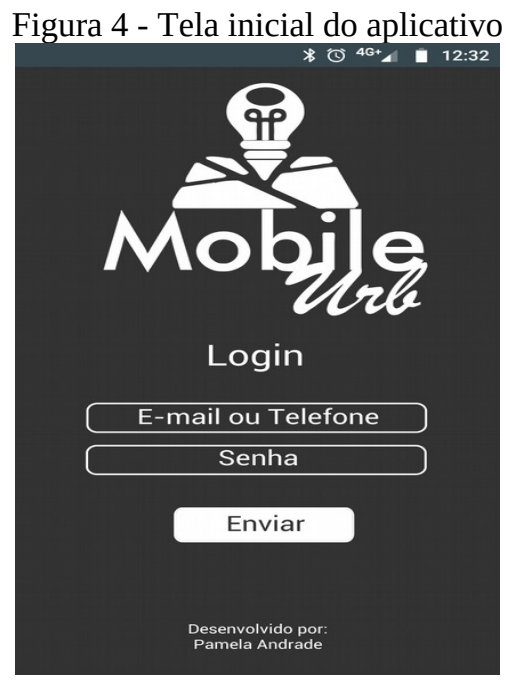

Fonte: Autores (2018) 


\subsubsection{Menu principal}

Na tela terá 5 opções de locomoção: “Ciclista”, “Transporte público”, “Transporte particular”, "Pedestre” e "Info RIO” basta "apertar" o serviço desejado para navegar e obter todas as informações necessárias ou digite a sua "origem” e "destino", que o próprio aplicativo te direciona quais melhores transporte a ser utilizado. $\mathrm{O}$ aplicativo ainda possui uma classificação como o trajeto mais barato, mais rápido e mais inteligente (conveniência $\mathrm{x}$ despesa do itinerário), conforme ilustrado na Figura 5 a seguir.

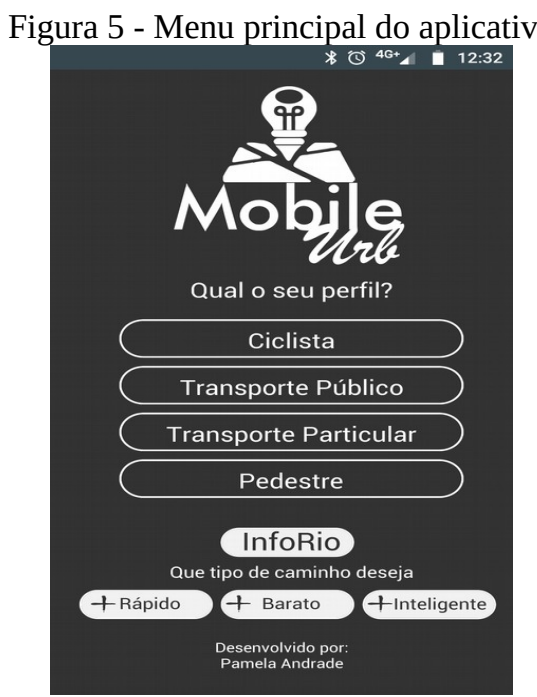

Fonte: Autores (2018)

\subsubsection{Ciclista}

Ao "clicar" no botão de ciclistas, ele será direcionado a todas as opções importantes para as pessoas que escolherem se locomover através desse transporte, o usuário é encaminhado as seguintes solicitações, ilustrada na Figura 6 a seguir:

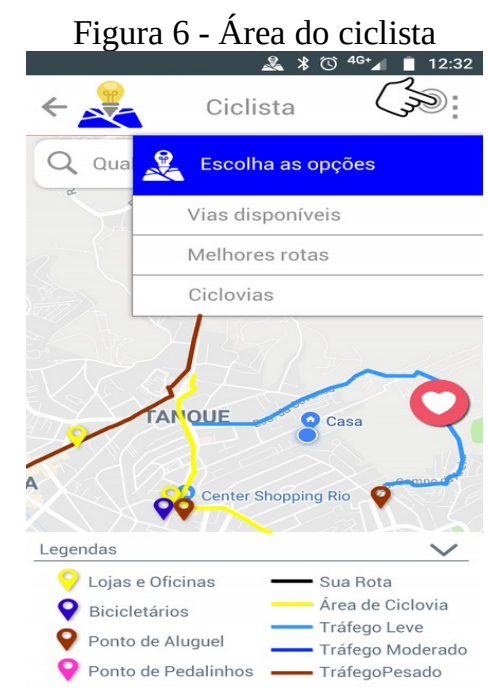

Fonte: Autores (2018)

- Quais vias disponíveis para acesso;

- Qual rota fazer para chegar a seu destino;

- O Próprio aplicativo calcula as rotas feitas pelos ciclistas;

- Quais lugares têm disponibilidade para aluguel de bicicleta e quantas 
bicicletas disponíveis;

- Bicicletários e paraciclos;

- Lojas e oficinas de bicicletas;

- Ciclovias recreativas / vias mais tranquilas para pedalar;

- Coleta dados de trajetos percorridos de bicicleta alimentando um banco de dados que cruza informações com infraestrutura existente;

- Mede a altimetria, velocidade média, calorias queimadas durante a pedalada, tempo, distância e ritmo.

\subsubsection{Transporte público}

Ao "clicar” no botão de Transporte público, ele será direcionado a todas as opções de transporte público existente como: “trem”, “metrô", “ônibus”, "BRT” e "VLT” e “origem e destino" após preencher o campo o aplicativo responderá o melhor trajeto e transporte a ser utilizado, como ilustrada na Figura 7 a seguir:

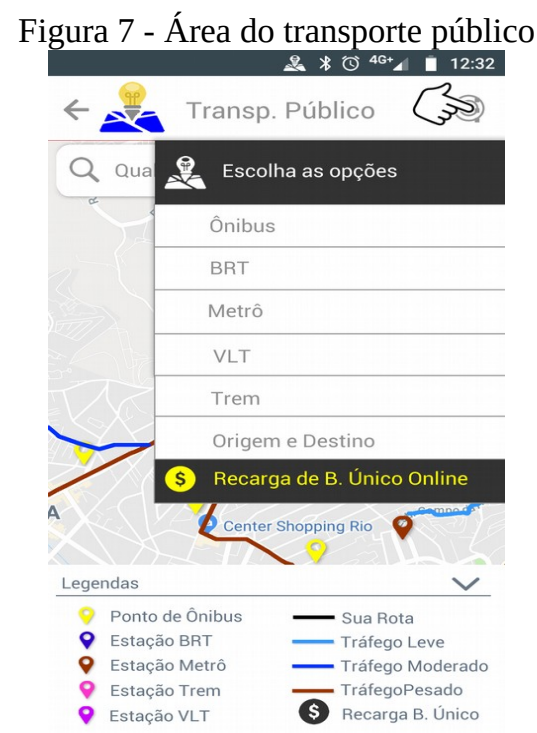

Fonte: Autores (2018)

- Fazer recarga de bilhete único online;

- Quais linhas disponíveis para seguir seu destino;

- Quais opções de transporte;

- Horários e rotas (menores trajetos, menores custos);

- Guia até o ponto de transporte e a hora de descer desse mesmo transporte;

- Notificação de antecedência para não perder o transporte;

- Situação de operação;

- Visualização no mapa a posição dos ônibus e mais de uma linha;

- Trajeto em tempo real;

- Mapa sobre pontos de ônibus, estações de trens, metrôs, BRT'S e VLT'S.

\subsubsection{Pedestre}

Ao "clicar" no botão de pedestre, ele será direcionado a todas as opções de entretenimento, acessibilidade e segurança que o aplicativo oferece para o cidadão, o usuário terá as seguintes opções como é ilustrada na Figura 8 a seguir: 
Figura 8 - Área do pedestre

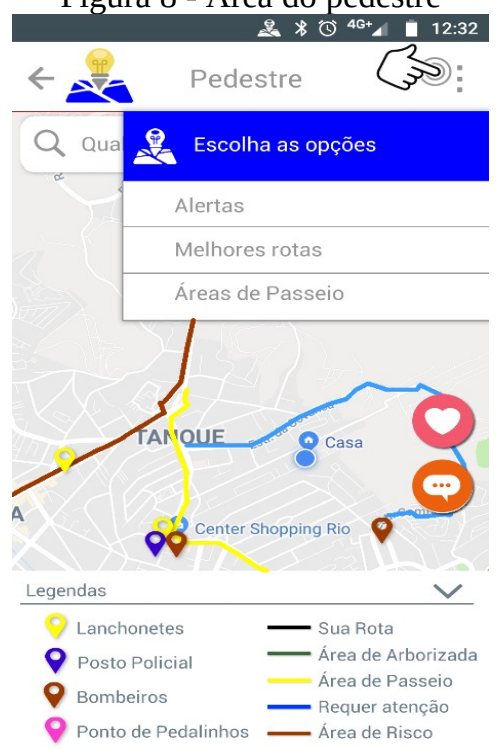

Fonte: Autores (2018)

- Melhores caminhos para andar a pé (Espaço verde, áreas comerciais, zonas com menor declive, áreas menos perigosas);

- Disponibiliza conversa com outros usuários;

- Disponibiliza o ranking de todo mundo que passou por aquele trecho;

- Faz chamada direta para: Polícia, SAMU, Bombeiro, Defesa Civil entre outros.

\subsubsection{Transporte particular}

Ao “clicar” no botão de Transporte particular, ele será direcionado a todas as opções de transporte existente como: "Uber”, "taxi”, "carro compartilhado", o usuário é encaminhado até o campo "origem e destino" após preencher o campo o aplicativo responderá o melhor trajeto e transporte a ser utilizado, como ilustrada na Figura 9 a seguir:

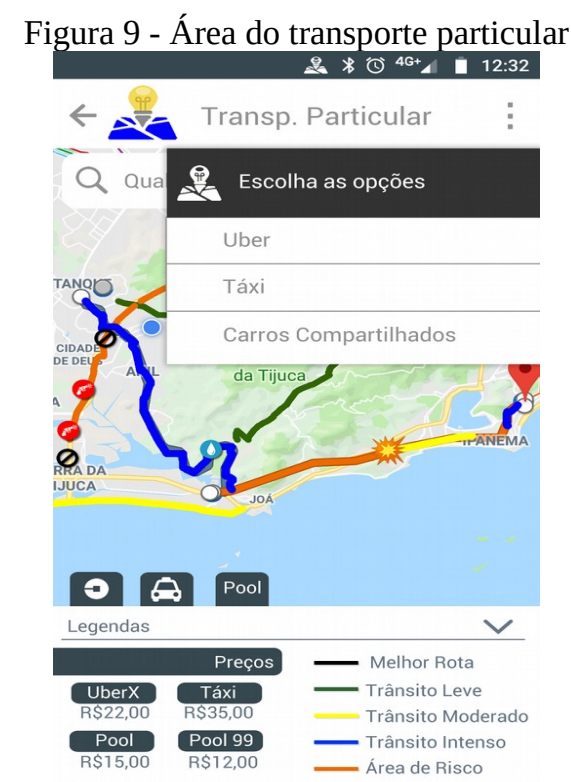

Fonte: Autores (2018) 
- Mapa das melhores rotas a seguir com todos os preços descritos;

- Identificação de todos os veículos disponíveis para compartilhar, situados na proximidade do usuário;

- Compartilhamento de localização;

- Reversa de utilização imediata de veículo.

\subsubsection{Info Rio}

Ao “clicar” no botão de trânsito, você terá todas as informações que um cidadão queria saber sobre o trânsito, como ilustrada na Figura 10 a seguir:

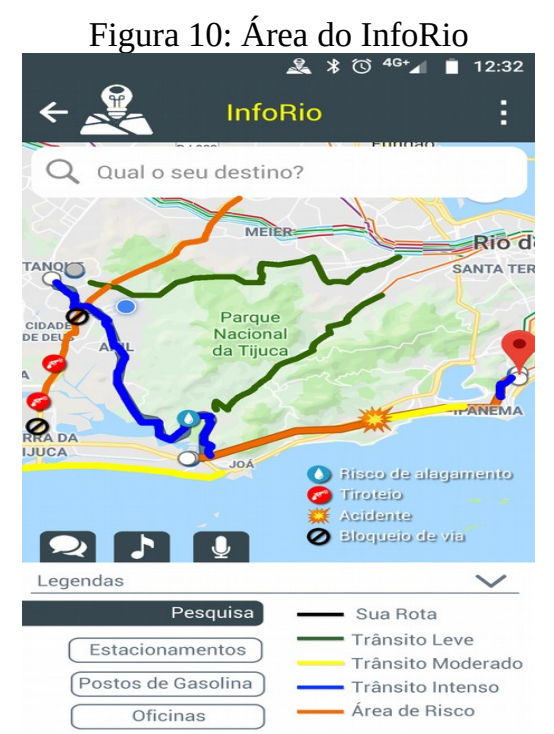

Fonte: Autores (2018)

- Informações em tempo real sobre alagamento, ou desastre natural;

- Vias bloqueadas;

- Áreas de Riscos;

- Mostra informações sobre o trânsito;

- Monitora os hábitos de direção do motorista (sem equipamento adicional) e estimula uma direção mais segura;

- Oferece a opção de se elaborar a rota da forma que for mais agradável;

- Indica estacionamento próximo como o valor a ser cobrado e horário de funcionamento;

- Possui integração com apps como WhatsApp, Telegram e Skype, além de integração com apps musicais, evitando o uso das mãos até mesmo para trocar de música. Possui comandos de voz intuitivos e funcionais;

- Permite calcular gastos com combustível e consertos. Além disso, conta com registros de abastecimento e lembretes de manutenções futuras;

- Planejamento de viagens;

- Informações sobre trajetos;

- QR Code.

Cada transporte possuirá um QR-Code (etiqueta de identificação), para liberar o acesso ao usuário, é necessário ativar o scanner do $Q R$ - Code e digitalizar, através da câmera do telefone celular, essa etiqueta de identificação ficará no acesso ao transporte.

Quando o usuário acessar o ícone "QR-Code” e fizer a leitura, ele direcionará para 
“Informações sobre trajetos” terá um histórico dos trajetos realizados, pagamentos efetuados, conforme a Figura 11 a seguir.

Figura 11 - Manual do QR- Code

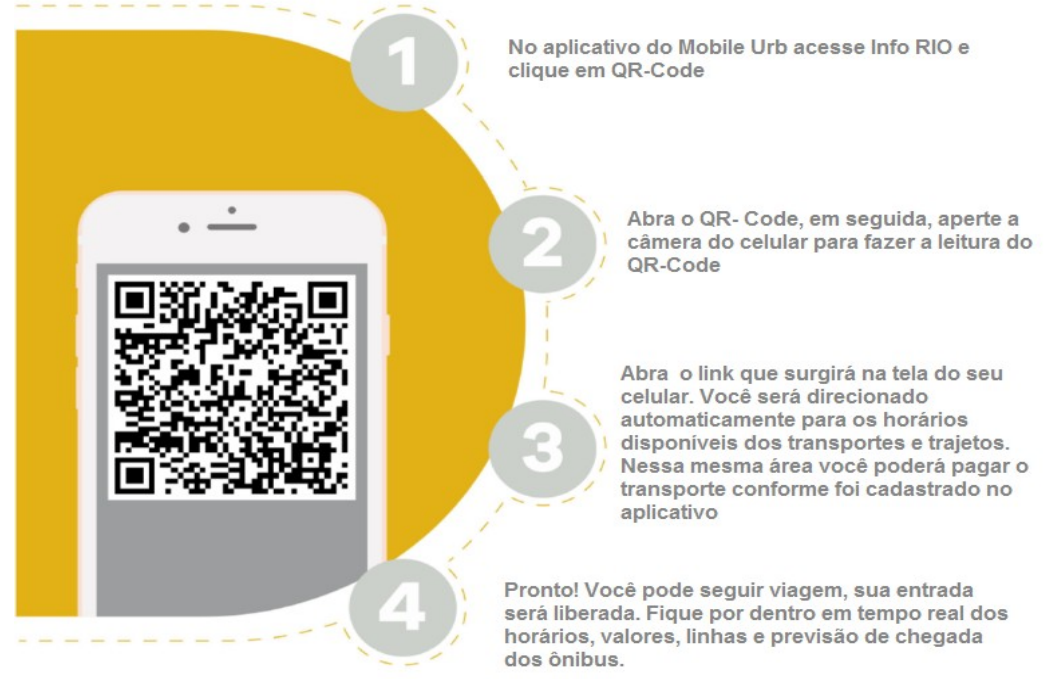

Fonte: Autores (2018)

\subsubsection{O QR-Code}

Ao elaborar a aplicabilidade do projeto numa área complexa composta por uma quilometragem de $1.255 \mathrm{~km}^{2}$, onde possuem:

- Ciclovia com extensão de 450 km;

- 440 Frotas de articulado de BRT e percorre 125 km de extensão;

- 204 Trens por uma malha de 270 km e 102 estações;

- Metrô Rio possui 41 estações, três linhas em atividade e 14 pontos de integração com 58 km de extensão;

- Rio ônibus possui em torno de 4625 ônibus em toda a cidade do Rio de janeiro;

- VLT é composta por 32 trens, com 44 metros de comprimento;

- 33.000 Taxis;

- 50.000 Uber.

Uma das soluções capazes independendo do grau de complexidade é a tecnologia do QR-Code. Para a execução desta etapa, foi necessário o acesso ao banco de dados da Fetranspor, mapeadas num sistema interno. Bastou que a equipe de Tecnologia da Informação, responsável pelo desenvolvimento do aplicativo, gere um $Q R$-Code equivalente a cada um desses transportes.

\subsubsection{Avaliação do uso do aplicativo}

A fim de medir, em tempo real a satisfação do cliente, uma opção será disponibilizada, abaixo nas "informações sobre trajetos", para que o usuário avalie a performance do aplicativo, do transporte coletivo, transporte particular, da mobilidade urbana e segurança ao optar entre nenhuma a cinco estrelas e, em facultativo, um texto resumido para maiores detalhes.

Ao final da utilização do aplicativo cada usuário que utilizar o serviço avaliará com uma nota e/ou informar um dado importante ao aplicativo para que os usuários fiquem cada vez mais satisfeitos e seguros, como é representado na Figura 12 a seguir. 


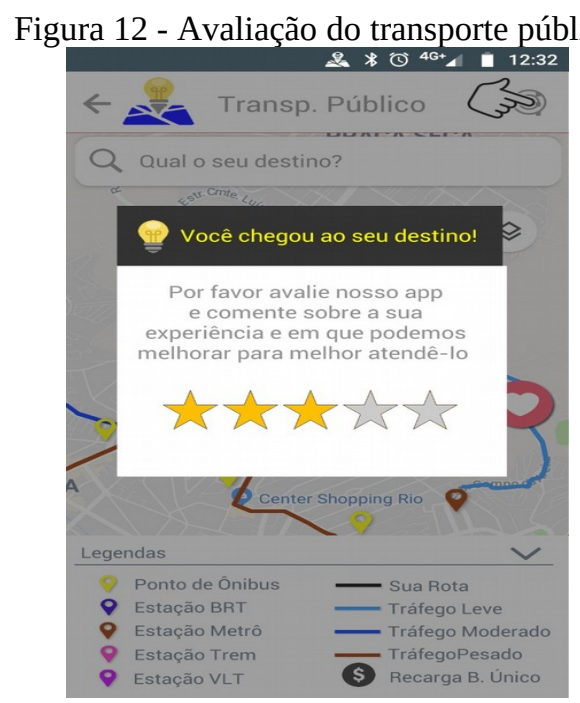

Fonte: Autores (2018)

\section{RESULTADOS ESPERADOS}

Com os constantes avanços da tecnologia e a facilidade de acesso aos smartphones, cada vez mais as pessoas estão conectadas. No contexto atual, os celulares não são somente uma maneira prática e rápida de comunicação. A seguir serão descritas as principais vantagens das ações propostas:

- Maior incentivo ao transporte coletivo;

- Maior segurança;

- Redução de carros particulares nas ruas;

- Redução de falhas operacionais;

- Redução de tempo no trânsito;

- Maior confiabilidade;

- Maior comodidade;

- Acessibilidade na palma das mãos;

- Maior facilidade de se locomover;

- Maior praticidade;

- Maiores possibilidades;

Tendo em vista os resultados esperados com a aplicação da proposta, as vantagens foram consideradas como ganho real para mobilidade urbana.

\section{CONSIDERAÇÕES FINAIS}

Este trabalho contemplou vários aspectos voltados às estratégias de gestão urbana do Rio de Janeiro por aprimorar acessibilidade que visam garantir a melhor locomoção de toda cidade, como também assegurar o bem-estar e a qualidade de vida dos cidadãos.

Acredita-se que é um grande passo o aplicativo mobile urb, a fim de medir a necessidade do cidadão, tornando a viagem mais fácil e mais rápida, além de mostrar que a ferramenta pode buscar informações importantes à gestão pública, a fim de trazer melhorias para a cidade.

Cidades inteligentes é um conceito que se encontra em alta no que tange planejamento de cidades, mesmo assim ainda causa divergência no meio acadêmico e apresenta um grande potencial de crescimento, de fato, pode realizar para que as cidades sejam cada vez mais eficientes com a utilização de tecnologia da informação, big data e internet das coisas. 
Entretanto, é importante salientar que a simples implementação desses conceitos não resolve todos os problemas existentes em uma cidade. Em contrapartida, o conceito de mobilidade urbana é bem antigo e familiar para muitos, mesmo que não conhecido por esse termo específico, e ainda assim, é um tema que necessita de estudos e soluções para enfrentar problemas que assolam, principalmente, as cidades em desenvolvimento, como o caso do Rio de Janeiro e que sofreram um processo acelerado de urbanização sem a infraestrutura necessária que a suportasse.

Os autores acreditam que a pesquisa sobre a viabilidade deve continuar e se aprofundar em modos de financiamento dessas iniciativas, seja através das Parcerias Públicas Privadas ou simples financiamento de empresas ou licitações públicas. Além disso, realizar testes em ambientes controlados dessas iniciativas a fim de entender melhor os gargalos e possíveis desdobramentos que elas levariam para a cidade como um todo.

\section{REFERÊNCIAS BIBLIOGRÁFICAS}

DIA, O. Aplicativos e tecnologia mudam a mobilidade urbana: Estudo mostra que ferramentas contribuirão para tirar até 65\% dos carros das ruas. 2016. Disponível em: $<$ https://odia.ig.com.br/_conteudo/rio-de-janeiro/observatorio/2016-03-01/aplicativos-etecnologia-mudam-a-mobilidade-urbana.html>. Acesso em: 23 set. 2018.

FERNANDES, Gilmar Soares. Impactos da Mobilidade Urbana na região metropolitana do Rio de Janeiro. 2015. 97 f. Monografia (Especialização) - Curso de Administração Pública, Instituto de Ciências Humanas e Sociais, Universidade Federal Fluminense, Volta Redonda, 2015.

GIFFINGER, R., FERTNER, C., KRAMAR, H., KALASEK, R., PICHLER-MILANOVIC, N., \& MEIJERS, E. (2007). Smart Cities: Ranking of European Medium-Sized Cities. Vienna, Áustria: Centre of Regional Science (SRF), Vienna University of Technology. Acesso em: 25 mar. 2018. from http://research.ku.dk/search/?pure=files \%2F37640170\%2Fsmart cities final report.pdf.

GLOBO, O. Tecnologia é aposta para melhorar o trânsito no futuro: Fórum promovido pelo DETRAN-RJ e pelo GLOBO discute soluções para aprimorar a mobilidade urbana. 2017. Disponível em: <https://oglobo.globo.com/rio/tecnologia-aposta-paramelhorar-transito-do-futuro-22008470>. Acesso em: 20 abr. 2018.

GLOBO. Sete cidades do mundo que são modelos de mobilidade urbana. 2018. Disponível em: <https://g1.globo.com/especial-publicitario/em-movimento/noticia/setecidades-no-mundo-que-sao-modelos-de-mobilidade-urbana.ghtml>. Acesso em: $10 \mathrm{abr}$. 2018.

GURGEL, Geraldo. Rio de Janeiro completa 453 Anos: Com mais de quatro séculos e meio, o Rio de Janeiro é uma das cidades mais belas do mundo e destino turístico brasileiro mais desejado por brasileiros e estrangeiros. 2018. Disponível em: < http://www.turismo.gov.br/últimas-notícias/10824-rio-de-janeiro-completa-453-anos.html>. Acesso em: 20 out. 2018.

HOLLER, J., TSIATSIS, V., MULLIGAN, C., AVESAND, S., KARNOUSKOS, S., \& BOYLE, D. (2014). From Machine-to-machine to the Internet of Things: Introduction to a New Age of Intelligence. Academic Press. Chicago

LEMOS, André. Cidades inteligentes. De Que Forma As Novas Tecnologias - Como A Computação em Nuvem, O Big Data e A Internet das Coisas - Podem Melhorar As Condições de Vida no Espaço Urbano, Bahia, v. 1, n. 4, p.1-4, 12. 
NOTÍCIAS, Senado. Mobilidade urbana é desafio para melhorar qualidade de vida, aponta audiência. 2018. Disponível em: < https://www12.senado.leg.br/notícias/materias/

2018/08/20/mobilidade-urbana-e-desafio-para-melhorar-qualidade-de-vida-apontaaudiencia>. Acesso em: 04 out. 2018.

PERO, Valéria; MIHESSEN, Vitor. Mobilidade urbana e pobreza no Rio de Janeiro. Séries Working Paper BNDES/ANPEC. Programa de Fomento à Pesquisa em Desenvolvimento Econômico (PDE). Working Paper n⿳0046. Rio de Janeiro: BNDES/ANPEC, set. 2012. Disponível em: <http://bit.ly/1SYugXv/>. Acesso em: 01 set. 2018.

RIBEIRO, Luiz Cesar de Queiroz; RIBEIRO, Marcelo Gomes (Org.). IBEU: Índice de BemEstar Urbano. Rio de Janeiro: Letra Capital, 2013.

SILVA, Antônio Nelson Rodrigués da, Marcela da Silva Costa, Márcia Helena Macedo, 2008, "Multiple views of sustainable mobility: The case of Brazil”, Transport Policy, v.15, n.6, pp. 350-360.

SONDA. Smart City: o que é e como aplicar esse conceito na sua empresa? 2017. Disponível em: <https:// https://www.sonda.com/br/>. Acesso em: 05 abr. 2018.

STATISTA. Internet usage worldwide - 2014. Disponível em: Acesso em: 15 out. 2018.

UNIÃO EUROPÉIA (UE). União Europeia apresenta exemplos de sucesso de cidades inteligentes durante Encontro dos Municípios com o Desenvolvimento

Sustentável. 2017. Disponível em: < https://eeas.europa.eu/delegations/brazil/24990/uniãoeuropeia-apresenta-exemplos-de-sucesso-de-cidades-inteligentes-durante-encontro-dos_ru>. Acesso em: 27 jul. 2018.

United Nations, Department of Economic and Social Affairs, Population Division. (2015). World urbanization prospects: The 2014 revision (ST/ESA/SER.A/366). Disponível em $<$ http://esa.un.org/unpd/wup/FinalReport/WUP2014-Report.pdf./>. Acesso em: 15 mar. 2018.

VILLARINO, Julia. Internet das coisas (IoT). 2017. Disponível em:

<https://www.proof.com.br/blog/internet-das-coisas/>. Acesso em: 15 abr. 2018.

WERKEMA. M. C. C. Ferramentas estatísticas básicas para o gerenciamento de processos. Belo Horizonte: Fundação Cristiano Ottoni, 1995.

XIMENES, Natália Lacerda Bastos, 2016, "Morfologia urbana: teorias e suas interrelações”, Dissertação de Mestrado, Escola Politécnica, Programa de Engenharia Urbana, UFRJ, 2016. 